\section{SOI: 1.1/TAS DOI: 10.15863/TAS International Scientific Journal Theoretical \& Applied Science}

\author{
p-ISSN: 2308-4944 (print) e-ISSN: 2409-0085 (online) \\ Year: $2015 \quad$ Issue: $04 \quad$ Volume: 24
}

Published: $30.04 .2015 \quad$ http://T-Science.org

SECTION 13. Geography. History. Oceanology. Meteorology.
Valeriya Shotaevna Khetagurova Associate Professor,

Candidate of geographical Sciences, Head of the Department of Social ecology and information law Russian state social university, Russia vhetag@yandex.ru

Ruslan Abdibaetovich Umaraliev Doctor Degree in Environmental Sciences and

Technology (PhD), employee of the Department of International Relations, Osh State University, The Republic of Kyrgyzstan umaraliev.ruslan@gmail.com

Galina Anatolyevna Bryukhanova senior lecturer

Russian state social university, Russia gal7717@yandex.ru

\title{
ON THE PROBLEM OF COMPLEX RECEPTIONS AND RESEARCH METHODS PATTERN THE RIVER NETWORK
}

\footnotetext{
Abstract: The presented method has been clarifying the relation landforms with the structures of the crust, that is, it occupies an intermediate position between geomorphology and geotectonics. As a result of the synthesis of the experience of previous research, the search for new ways of summarizing data on structural features of the pattern of the river network, has formed a set of coherent instructional techniques analyze the pattern of the river network, a technique called erosion-structural analysis. Long-term experimental studies the authors based on the detailed design of an extensive cartographic materials, including physical-geographical maps of different scales, geological and tectonic maps and charts; metallogenic maps, satellite images. The place of erosion-structural analysis in solving the problem of knowledge communication between topography, geological structure and tectonics and practical significance.

Key words: method of erosion-structural analysis, erosion systems, river network, tectonic faults.

Language: Russian

Citation: Khetagurova VS, Umaraliev RA, Bryukhanova GA (2015) ON THE PROBLEM OF COMPLEX RECEPTIONS AND RESEARCH METHODS PATTERN THE RIVER NETWORK. ISJ Theoretical \& Applied Science 04 (24): 27-35.

Soi: http://s-o-i.org/1.1/TAS*04(24)5 Doi: crosstef http://dx.doi.org/10.15863/TAS.2015.04.24.5
}

\section{К ВОПРОСУ О КОМПЛЕКСЕ ПРИЕМОВ И МЕТОДОВ АНАЛИЗА РИСУНКА РЕЧНОЙ СЕТИ}

Аннотация: Представленная методика занимается выяснением соотношения форм рельефа со структурами земной коры, то есть она занимает промежуточное место между геоморфологией и геотектоникой. В результате синтеза опыта предыдущчих исследований, поиска новых путей обобщения данных о структурных особенностях рисунка речной сети, сформировался комплекс последовательных методических приемов анализа рисунка речной сети, получивший название методики эрозионноструктурного анализа. Многолетние экспериментальные исследования авторов базируются на детальной проработке обширного картографического материаль, включая физико-географические карты разных масштабов, геологические и тектонические карты и схемы; металлогенические карты, космические снимки. Определяется место эрозионно-структурного анализа в решении проблемы познания связи между формами рельефа, геологической структурой и тектоникой и практическая значимость.

Ключевые слова: методика эрозионно-структурного анализа, эрозионные системы, речная сеть, тектонические нарушения.

\section{1. Введение}

Крупнейшие достижения современной науки и техники - глубинное бурение, сейсмическое зондирование, высотные и космические съемки, геофизические исследования дна морей и океанов и многие другие дали мощный толчок развитию наук и Земле. Сформировалось учение о новой глобальной тектонике, появилось значительное количество новых представлений в области магматизма и металлогении. Достижения

ISPC The Combination of Technology \& 
смежных геологических наук дали возможность установить тесную корреляцию рельефа поверхности с ее глубинным строением, что явилось стимулом для развития структурногеоморфологических исследований. Значительный шаг в развитии проблем геоморфологии, тектоники, структурной геологии сделало применение аэрофотометодов, а космическая фотография позволила увидеть крупные геоструктуры земной коры, о которых тектонисты могли только догадываться. Проходка свехглубокой скважины на Кольском полуострове поставила под сомнения существование под континентами базальтового слоя, присутствие которого, как казалось ранее, позволяет объяснить многие явления в строении и развитии земной коры. Таким образом, каждый новый метод исследования позволяет в меру своих возможностей подтвердить или поставить под сомнение казалось бы решенные проблемы, или предположить их более широкое решение, или, наконец, установить новые факты и предложить новые гипотезы.

Давно известно, что часто речные долины могут быть приурочены к тектоническим нарушениям, вместе с тем не было до недавнего времени составлено ни одной представительной структурной или тектонической карты, основанной на анализе рисунка речной сети. Было заманчиво и практически перспективно ввести в геологическое производство этот огромный массив информации. Проведенное исследование показало, что вся масса сложившейся речной сети, обычно не привлекающая внимание исследователей, поддается геометризации, то есть состоит из сочетания геометрически выдержанных и относительно простых элементов - эрозионных систем, которые в свою очередь соответствуют системам тектонических трещин. Этот факт, подтвержденный исследованиями ряда территорий, резко поднял значимость тектонического фактора в формировании речной сети, особенно для горных стран и открыл возможность составления представительных структурных и тектонических карт различных участков земной коры, имеющих развитую речную сеть, отраженную на географической карте. В большинстве случаев составленные эрозионно-структурные карты обладают хорошей сходимостью с тектоническими элементами, заимствованными с одномасштабных геологических карт, и являются в три-четыре раза более информативными. Последнее обстоятельство позволяет решать на новом и полученном независимым методом фактическом материале значительное количество задач.
Для апробации данной методики был выбран Памир и прилегающие к нему территории $[24,35]$. Полученные результаты исследования показывают, что данные эрозионно-структурного анализа по этому региону имеют как научное, так и практическое значение. На примере Памира показана возможность использования данных эрозионно-структурного анализа для совершенствования тектонической основы металлогенических карт и данный метод может быть использован в качестве вспомогательного метода исследования при поисках месторождений полезных ископаемых.

\section{2. Методика}

Методика эрозионно-структурного анализа подразделяется на несколько методов исследований речной сети методов, дающих однозначные и стабильные результаты, обладающие хорошей сходимостью и структурно-тектоническими смыслом, что подтверждено на основании опыта авторов, накопленного при анализе речной сети на многих сотнях географических карт различного масштаба различных регионов.

\section{1 Классификация эрозионных систем}

Необходимым условием проведения эрозионно-структурного анализа является использование классификации эрозионных систем, разработанной на основании многолетнего опыта детальной проработки обширного картографического материалы. Классификация эрозионных систем является базой, знание которой является необходимой предпосылкой для успешного дешифрирования речной сети любого региона. Типичными признаками, лежащими в основе распознавания видов эрозионных систем для целей их дальнейшей классификации, являются системность, выдержанность, преобладание и обособленность. На сегодняшний день эта классификация состоит из 48 видов эрозионных систем, 22 классов и 10 типов [20, 201].

Поскольку каждая из эрозионных систем несет определенные, только ей присущие закономерные черты, представилось рациональным составить классификацию эрозионных систем со ступенчатым подчинением, приняв за исходную единицу вид эрозионной системы, который совместно с родственными видами образует класс, а последние группируются в типы. Предлагаемая классификация уже проверена при эрозионноструктурном анализе некоторых горных регионов и не представляется громоздкой, так как наименование эрозионной системы в зависимости от необходимости может быть сведено к двум или даже одному термину. Как показывает практика, классификация охватывает 
практически все виды существующих эрозионных систем, но вместе с тем по мере накопления в процессе последующих исследований ее общей структуры. Составлена она в виде "Атласа видов эрозионных систем", который значительно облегчает проведение эрозионно-структурного анализа. Поскольку данная классификация вобрала в себя опыт исследования сотен карт, она сама по себе оказывается методически сильным орудием в проведении эрозионно-структурного анализа. Уже первый взгляд на карту речной сети убеждает нас в том, что она не является монотонной, предопределенной только течением воды в направлении сверху вниз по кратчайшим линиям. Наоборот, речная сеть оказывается разнообразной по своему рисунку, который уже замечается даже взглядом начинающего исследователя. Бегло просмотрев речную сеть, мы можем приступить к ее анализу, то есть выявлению геометрически закономерных систем.

2.2 Метод постепенного выявления

В любой речной сети, даже развивающейся на субстрате с весьма сложным тектоническим строением, всегда имеется доминирующая эрозионная система с достаточно четко выраженными многочисленными геометрическими элементами этой системы. Выделение такой наиболее броской и заметной эрозионной системы, как правило, не вызывает особенных трудностей, a eе оконтуривание на карте линиями двойной толщины (или цветом) намечает первую из искомых эрозионных систем региона. Практически оказывается, что такие броские и геометрически четкие эрозионные системы выделяются сразу в нескольких местах карты. Одновременно оставшаяся речная сеть, обозначенная тонкими линиями, упрощается и в таком остаточном рисунке, в свою очередь выявляются броские системы, которые оконтуриваются.

Анализ в замедленном темпе производится в несколько этапов до тех пор, пока оставшиеся фрагменты не теряют достаточно четко выраженную геометричность. Такая остаточная сеть относится к мозаичному типу и должна рассматриваться уже в более крупном масштабе. Еще и еще раз просмотрев оставшуюся не геометризованной речную сеть, сопоставив ее с “Атласом видов эрозионных систем”, исследователь, в конце концов, придет к мнению об исчерпании данных эрозионно-структурного анализа для изучаемой территории. Заключительным этапом исследования является сопоставление данных эрозионно-структурного анализа с данными предшествующих исследований, отраженных на равномасштабных геологических картах. Следует подчеркнуть условие равномасштабности сравниваемых документов, так как при этом в известной мере соблюдается соответствие рангов сравниваемых структур, часто нарушаемой при составлении мелкомасштабных карт путем трансформации карт крупномасштабных, когда например, рудные нарушения переносятся из масштаба в масштаб, невзирая на их тектонический ранг.

\section{3 Метод разномасштабных карт}

Выявление геометрических закономерностей в строении речной сети и дальнейшая интерпретация полученных данных с целью выявления закономерностей тектонического строения изучаемой территории достаточно достоверно производится с помощью вышеописанного метода. Однако выявление основных черт строения территории еще не обеспечивает выявления всех причин и условий ее формирования, а тем более истории тектонического развития, кинематики системы и динамической обстановки. Для решения подобных задач в каждом отдельном случае желательно получить сведения об обстановке в более широком регионе, в котором данная территория играет роль лишь сравнительно небольшой части, зависимой от окружающей ситуации. Вопрос о том, карты каких масштабов необходимо и достаточно исследовать, чтобы получить достоверную информацию о строении интересующей нас территории вряд ли можно считать удовлетворительно решенным. Некоторые ученые [3, 107] вообще считают, что “анализ речной сети ... должен опираться не на какую-либо одну характеристику ..., а на общую структуру", что применительно к исследованию эрозионных систем приобретает и четко выраженный структурно-тектонический смысл. Ряд исследователей отмечает, что в строении речной сети и тектонических структурах можно выделить единые морфометрические закономерности, которые могут быть полезными и при изучении конкретной территории. Так, Пиотровский М.В. считает, что длины новейших структур (и, следовательно, масштабы соответствующих карт) различных порядков изменяются в строго определенных соотношениях: для долин IX - XV порядков она соответственно равна $1,3,10,30,100,300$ и 1000 км $[11,14]$. Эти закономерности показывают, что длины структур соответствуют длинам рек, взятым через порядок, то есть имеют место единые морфометрические закономерности в строении речной сети и тектонических структурах. Иными словами, широко применяемое в тектонике направление исследования «от общего к частному» столь же 
широко должно применяться и при эрозионноструктурном анализе.

Перед проведением эрозионно-структурного анализа на картах разного масштаба в направлении от более мелкого масштаба к более крупному, необходимо убедиться в их кондиционности, так как карты, созданные механическим увеличением, не обладают повышенной информативностью. В качестве мелкомасштабных карт, используемых для начальной стадии анализа, пригодны физикогеографические карты из общих региональных атласов, независимо от системы проекции, так как последняя искажая систему в целом, существенно не изменяет ее облика и не сказывается на результатах распознавания. Для наиболее успешного решения построения эрозионно-структурных карт следует иметь достаточно разнообразный набор масштабов карт. При этом начинать исследования следует с карт более мелкого масштаба, на которых представляется возможным выявить наиболее общие черты закономерности в строении речных долин региона и установить положение участка при более крупномасштабных исследованиях.

\section{Результаты}

Мнения исследователей об общей структуре Памира достаточно противоречивы, особенно в области интерпретации фактических данных, но в тоже время сами фактические данные находятся в хорошей сходимости с данными эрозионноструктурного анализа, которые являются неискаженным отражением природных процессов. Для оценки реальности существования разрывных структур, выявленных методами эрозионно-структурного анализа мы сопоставили полученные результаты с независимыми данными других исследователей этих структур. Для идентификации разрывных структур района, соответствующих рангу выбранного масштаба, воспользуемся исследованием Суворова А.И., посвященного глубинным разломам платформ и геосинклиналей $[15,201]$. Сопоставление эрозионных структур с расположением глубинных разломов показывает, что имеет место весьма хорошее совпадение элементов эрозионных систем с глубинными разломами. В северной части на границе Памира с дугами Тянь-Шаня, намеченный глубинный разлом широкой дугой охватывает сооружение Памира, продолжаясь в области предгорных равнин. Фрагменты гребенчато-двусторонней прямой эрозионной системы, совпадающие с глубинным разломом, в средней части продолжаются к востоку, формируя полосовую систему. Очевидно, по данным эрозионноструктурного анализа, глубинный разлом не только огибает Памир, но и раздваивается и продолжается в западном направлении, где располагаются тождественные гребенчатые эрозионные системы. Чем ближе располагаются глубинные разломы к центральному формирующему «штампу» Памира, тем круче они изгибаются, совпадая со столь же изогнутыми долинами-трещин. Следующий глубинный разлом заканчивается как раз в том месте, где по данным эрозионно-структурного анализа находится решетчато-прямоугольная эрозионная система, типичная для области развития магматических пород. Следуя на югозапад по системе долин, другое окончание этого разлома отмечается в месте нахождения круглых эрозионных систем, часто совпадающих с вулканическими аппаратами. Два следующих глубинных разлома, прилегающих к центральному блоку, охватывают его с запада, прослеживаются вдоль эрозионной системы и неожиданно заканчиваются в средней части региона, как впрочем и приуроченные к ним долины. Центральное поднятие «штамп» Памира оконтурено глубинными разломами (в понимании Суворова А.И.) с юга, запада и севера, четко следуя долинам рек, прерываясь на югозападе, где его следует продолжить как это подсказывают данные эрозионно-структурного анализа. Восточная граница поднятия собственно Памира совпадает с протяженным глубинным разломом северо-западного простирания, который выклинивается в области распространения решетчато-прямоугольной эрозионной системы. Внутри поднятия Памира глубинные разломы ориентированы в широтном направлении, совпадают с одноименными долинами и, в общем-то, выпадают из общего структурного плана Памира, представляя фрагменты возможно более древних структур, запечатленных в жестких породах фундамента. На юге глубинный разлом частично совпадает с дуговой долиной, а затем переходит в краевую часть поднятия Памира. Очевидно, и здесь имеет место раздвоение (или слияние) двух глубинных разломов и их вероятное положение отмечено на карте.

Таким образом, сопоставление эрозионных структур с расположением глубинных разломов показывает, что имеет место весьма хорошее их совпадение, которое оценивается в 75-80\% при значительно большой информативности эрозионных структур. Не менее интересным оказывается сопоставление эрозионных систем Памира с простиранием относительно мелких нарушений - зон раздробления, даек, рудных жил и т.п.. Сравнение, сделанное для центральной части и в несколько более крупном масштабе, показывает, что имеет место очень хорошее совпадение положения и простирания мелких 
структурных элементов с основными чертами эрозионных систем (более 60\%). Следует обратить внимание на две особенности строения, выявленные при этом сравнении. Во-первых, часть рудоносных структур Памира оказалась ориентированной в северо-западном направлении, то есть том направлении, которое было получено при эрозионно-структурном анализе в масштабе 1:5 000 000, и, во-вторых, в отсутствии достаточно представленных данных для подтверждения существования меридиональных структур. Их количество не выходит за пределы обычной нормы меридиональных и широтных структур, возникающих повсеместно под влиянием ротационных сил вращающейся Земли.

\section{4. Обсуждение}

Представленная нами методика эрозионноструктурного анализа примыкает к тому разделу геологии, который занимается выяснением соотношения форм рельефа со структурами земной коры, то есть она занимает промежуточное место между геоморфологией и геотектоникой. Это направление в геологических науках было предвосхищено в ряде теоретических и практических работ наиболее прогрессивных исследователей. Один из ведущих тектонистов Хаин В.Е. значительное внимание уделял развитию основ структурногеоморфологического метода. Он считал, что основные принципы структурногеоморфологического метода заключаются в выявлении связей новейших структур и рельефа, в выявлении специфики связей новейших структур и рельефа, в выявлении специфики выражения новейших деформаций в ландшафте (с учетом климатической зональности), в установлении соотношений между новейшими и более древними структурными планами $[18,20]$. Он даже отмечал несколько структурногеоморфологических зон, в каждой из которых, по его мнению, должен применяться специфический комплекс методов исследования. Следовательно, в том числе может применяться и разработанный нами метод эрозионноструктурного анализа.

Несколько с иных позиций подходила к этому интересующему нас вопросу Аристархова Л.Б., которая в исследовании о методах структурно-геоморфологических документов выделяла шесть основных методов: специальное геоморфологическое картографирование в комплексе со структурно-геоморфологическим дешифрированием, изучение строение речных долин, в том числе долин временных водотоков, изучение рыхлых новейших отложений, сопоставление геолого-геоморфологических профилей и создание метода изучения линейных элементов рельефа. Среди итоговых документов она рекомендовала создание карты линейных элементов рельефа с изолиниями их густоты и розами-диаграммами. Результаты комплексного анализа и каждого из отдельных методов должны быть отражены на итоговой карте тектонических структур региона. Под структурногеоморфологической картой Аристархова Л.Б. понимала любую карту, составленную на основании применения одного или нескольких частных методов структурногеоморфологического анализа и отражающую как исходный фактический материал, так и частные выводы о тектонической структуре района $[2,19]$. Несколько сдержаннее относился к проблеме «долина реки - тектоническое нарушение» Леонтьев Г.И.. В своей работе “О тектоническом обосновании морфометрических методов выявления тектонических структур" он считал, что развитие речной сети обусловлено расположением структур, но ее деятельность в свою очередь изменяет структуры, что приводит к экзогенным движениям и, в конечном счете, изменяет речную сеть [9, 48]. Наиболее определенно и четко о задачах установления связи форм рельефа с тектоническим строением высказался советский геоморфолог Пиотровский M.В., который считал морфометрическое картирование назревшим передовым направлением геолого-геоморфологических исследований. Он считал, что геологоморфологическое картирование вступило в новый этап - гораздо более полного отражения строения Земли, чем ранее $[11,16]$. Неполнота структурных данных, особенно решетчатых систем планетарных разломов, наличие их невскрытых звеньев делало геологические и тектонические карты того времени не до конца полноценными, не позволяющими установить целостные системы явлений тектономорфогенеза. Морфотектоническое картирование по космоснимкам и топокартам, проводимое путем «жесткой рисовки», выдвигается сейчас как быстрый эффективный метод, который сыграет существенную роль в развитии нового системного картирования. Так же нельзя здесь не отметить работу Философова В.П. “Основы морфометрического метода поисков тектонических структур" [17, 23].

Не только высказанные ранее прогнозы и предложения о развитии науки позволяют определить место эрозионно-структурного анализа и решаемых им проблем. В системе геологических знаний целый ряд решаемых практических работ, произведенных в смежных областях, тесно примыкает к интересующей нас области исследования. Занимаясь вопросами планетарной трещинноватости, Щульц С.C. 
пришел к выводу, что с простиранием планетарной трещинноватости связываются многие элементы рельефа и гидрографической сети $[23,37]$. Еще более острую и определенную задачу сформулировал Русанов А.Б. развивающий тектоно-геоморфологические методы прогнозирования месторождений полезных ископаемых. Им ставился вопрос о введении в геологическую практику и терминологию понятия о рудоуказателях, то есть различных объектов геологического, геоморфологического и географического характера, чаще всего линейных, отмечающих направление на тот или иной рудный район или месторождение $[13,10]$. Последние, занимая правофланговое положение по отношению к рудоуказателям, «нацелены» со стороны на участки локализации полезных ископаемых. Можно считать, что материал о связи эрозионных систем Памира и сопредельных территорий с металлогенией является современным ответом на ранее поставленную задачу [19, 629].

Целесообразно и своевременно перечислить некоторые исследования, стоящие на грани применения метода эрозионно-структурного анализа. Например, Розанов А.Н., проводя поисковые работы на нефть обратил внимание, что расположение древних долин хорошо согласуется с современной гидрографической сетью: "Почти все реки имеют своих древних аналогов, - автор отмечал - большую тектономорфность древнего рельефа..." [12, 104]. И все-таки применял для поисков древних долин не разработки типа эрозионно-структурного анализа, а дорогостоящие геофизические методы разведки. Ананьев Г.С. исследовал степень расчлененности рельефа с целью выработки критериев для поиска гидротермального оруденения. Он отмечал, что тектоническая трещинноватость предопределяет расположение как речных долин, так и гидротермальных месторождений $[1,134]$. Им разработан критерий густоты расчлененности и сказано, что для контроля анализа расчлененности следует применять совместно другие методы структурной геоморфологии, но в то же время они так и не были разработаны. Почти точно сформулирована задача связи рудных месторождений с речными долинами в исследованиях Хрипкова А.В. и Волкова Е.Л. в работе "Некоторые особенности долин как геоморфологические поисковые критерии рудных месторождений”. Авторы говорят: "Причинами эрозионных аномалий... могут явиться нарушения, ... поэтому поиски рудных месторождений ... следует проводить в долинах". “Задача сформулирована, возможное решение предоставлено, а методики исследования нет" - отмечают они. [21, 19]. В коллективном исследовании под эгидой Фаворской М.А. "Глобальные закономерности размещения крупных рудных месторождений”, $[16,20]$, и в работе Волчанской И.К., Кочневой H.T., и Сапожниковой Е.Н., в которой рассматривается морфоструктурный анализ при геологических и металлогенических исследованиях - отдельные виды речной сети приводятся как указатели структур [4, 175], а метода их распознавания, вычленения и толкования нет. Имеются и специальные обобщающие работы $[25,16]$, в которых речные бассейны рассматриваются как с позиций формирования стока и его энергетики, так и во взаимосвязи с процессами рельефообразования. В ходе исследований показана высокая и разнообразная информативность различных характеристик речных систем по отношению к морфоструктурам и современной тектонике. Однако главными их недостатками всегда оставались уровень теоретической базы, высокая субъективность и большая трудоемкость анализа.

Большинство работ по анализу речных систем относится к 1960-1970 гг. Уже к концу 1980-х гг. исследования по этому направлению в России были практически свернуты, большей частью из-за отсутствия адекватной информационной и технологической базы. В ходе геоморфологических исследований было выполнено большое число работ по изучению строения и генезиса речных долин. Установлено, что гидрографическая сеть нередко сопряжена с границами геологических структур и избирательно препарирует разнотипные литофациальные комплексы отложений, быстро, но неоднозначно реагирует на проявления современной тектоники [14, 52]. В 1990 г. был предложен термин “структурная гидрография" $[8,190]$. В качестве обзоров по данной тематике можно назвать монографии: "Речные системы (на примере Дальнего Востока)" [6, 140] и “Бассейновая концепция в природопользовании" $[7,5]$. В настоящее время в рамках структурной гидрографии разрабатываются модели нового поколения, ориентированные на решение как фундаментальных, так и прикладных задач гидрологии [22, 14].

Бурное развитие геоинформационных технологий и средств дистанционного зондирования в последние десятилетия привело к появлению цифровых моделей рельефа в виде общедоступных глобальных покрытий среднего масштаба и высокого качества. В результате почти любой фрагмент суши становится одинаково доступным для морфометрического анализа. Цифровые модели рельефа разного масштаба представляют собой специальные обработки результатов цифровой космической 
съемки и обладают важным преимуществом генерализацией и наглядностью изображения многих геоморфологических объектов, делая их доступными для прямого восприятия широкого круга специалистов. Важным качеством цифровых моделей рельефа является и то, что они, в отличие от топографических карт, содержат первичную информацию. Растровый способ организации данных в цифровых моделях рельефа вместе с наглядностью дает огромные преимущества при компьютерной обработке. Широкое внедрение цифровых моделей рельефа приводит к появлению качественно новых возможностей в целом ряде направлений наук о Земле - геологии, геоморфологии, географии, гидрологии и др. [5, 29]. Опыт использования цифровых моделей рельефа в эрозионноструктурном анализе может явиться следующим шагом в развитии представленного нами метода исследования.

Следовательно, из всего вышесказанного можно сделать вывод о том, что новый разработанный нами метод, названный эрозионно-структурным анализом, оказался на острие морфоструктурных по методу и тектоническому по результатам исследований. Еще в 1966 году Пиотровский М.В. считал, что морфотектоническое картирование обогатит изучение рельефа и даст более точную основу для картирования тектонически предопределенных ландшафтов [10, 240]. Планы решетчатых систем разрывных нарушений, связанной с ними долиной сети и морфоструктур и соотношение их с коромантийными уровнями представляют реальную основу программирования задач на ЭВМ.

\section{Заключение}

Изложенные выше приемы и методы анализа рисунка речной сети при соблюдении их последовательности и принципов позволяет достаточно уверенно и однозначно выделить определенное количество эрозионных систем, обладающих выдержанными геометрическими свойствами. Поскольку эрозионные системы являются производными от существующих систем тектонических нарушений, то это допускает возможность решать тектонические задачи. Сказанное позволяет заключить, что эрозионные системы отражают тектоническое строение земной коры и ее структуру.

В результате выявления геометрических закономерностей в строении речных сетей при анализе обширного картографического материала, а также обобщение данных других исследователей в этом направлении была составлена наиболее представительная классификация эрозионных систем со ступенчатым подчинением. В результате проведенного эрозионно-структурного анализа горной территории можно вывести следующие основные выводы:

1. на примере территории Памира была апробирована новая методика, названная эрозионно-структурным анализом, состоящая из двух методов - метода постепенного выявления и метода разномасштабных карт;

2. на основании проведенного анализа рисунка речной сети и сопоставления выявленных эрозионных систем с тектоникой были составлены эрозионно-структурные карты Памира и прилегающих территорий в разных масштабах. Характеризующиеся хорошей сходимостью с тектоническими элементами, заимствованными с одномасштабных геологических карт, эрозионно-структурные карты в 3-4 раза более информативны, что позволяет решать на новом и полученным независимым методом фактическом материале ряд практических задач.

Следующим этапом исследований на основе методики эрозионно-структурного анализа будет проведение работ с целью показа возможности использования данных эрозионно-структурного анализа для совершенствования тектонической основы металлогенических карт, для обоснования вопроса о его использовании в качестве вспомогательного метода исследований при поисках месторождений полезных ископаемых.

Кроме того, следует отметить, что появление цифровых среднемасштабных глобальных данных о земной поверхности и развитых общедоступных программных средств их обработки делает актуальным переход от функционального к структурнофункциональному моделированию в качестве базового инструмента гидрологии суши. В настоящее время этот переход уже начался и активно развивается. С другой стороны, разработанные в классической геоморфологии представления об энергии рельефа, структуре речных бассейнов и их взаимосвязи с новейшей тектоникой могут теперь быть проверены на большом статистическом материале и получить дальнейшее развитие на основе внедрения цифровых моделей рельефа и новых алгоритмов их обработки. Поэтому в перспективе дальнейших исследований с целью усовершенствования методики эрозионноструктурного анализа планируется использование цифровых методов рельефа. 


\section{References:}

1. Anan'ev GS (1973) Analiz raschlennosti rel'efa pri poiskakh gidrotermal'nogo orudeneniya. Voprosy geografii. - 1973 - Sb. 92. - pp.132142.

2. Aristarkhova LB (1968) O metodakh strukturno-geomorfologicheskogo analiza i soderzhanie itogovykh strukturnogeomorfologicheskikh kartograficheskikh dokumentov. Materialy Khar'kovskogo otdeleniya Geograficheskogo obshchestva Ukrainy. - 1968 - Vyp.6. - pp.17-24.

3. Borsuk OA (1974) Sistemnyy podkhod k analizu rechnykh sistem. Voprosy geografii, sb. 93. Moscow: Nauka, 1974. pp.107-113.

4. Volchanskaya IK, Kochneva NT, Sapozhnikova EN (1975) Morfostrukturnyy analiz pri geologicheskikh i metallogenicheskikh issledovaniyakh. Moscow: Nauka, 1975, pp. 211.

5. Gartsman BI, Galanin AA (2011) Strukturnogidrograficheskiy i morfometricheskiy analiz rechnykh sistem: teoreticheskie aspekty. Geografiya i prirodnye resursy. — 2011 — № 3. - pp. 27-37.

6. Karasev MS, Khudyakov GI (1984) Rechnye sistemy (na primere Dal'nego Vostoka) Moscow: Nauka, 1984. - 143 p.

7. Korytnyy LM (2001) Basseynovaya kontseptsiya v prirodopol'zovanii. - Irkutsk: Izd-vo Instituta geografii SO RAN, 2001. $163 \mathrm{p}$.

8. Korytnyy LM, Bezrukov LA (1990) Vodnye resursy Angaro-Eniseyskogo regiona. Novosibirsk: Nauka, 1990. - 214 p.

9. Leont'ev GI (1971) O teoreticheskom obosnovanii morfometricheskikh metodov vyyavleniya tektonicheskikh struktur. Voprosy morfometrii, Saratov, SGU, 1971, vyp. 3, pp.43-51.

10. Piotrovskiy MV (1966) Nekotorye zakonomernosti svodovo-blokovoy morfotektoniki. - V kn.: Problemy neotektonicheskikh dvizheniy i noveyshikh struktur zemnoy kory. - M.oscow: Nauka, 1966, -p.248.

11. Piotrovskiy MV (1964) Voprosy metodiki obzornogo morfometricheskogo analiza. - V sb.: Voprosy geologii Pribaykal'ya i Zabaykal'ya. - Chita, Izdatel'stvo Geograficheskogo obshchestva, 1964, p.14-26.

12. Rozanov AN (1964) O geologicheskoy prirode fotona na kosmicheskikh snimkakh. Sovetskaya geologiya - 1964 - № 1 - pp.100-106.
13. Rusanov AB (1981). Geomorfologicheskie metody vyyavleniya struktur rudnykh poley. V sbornike: Trudy SKGMI, Ordzhonikidze, 1981, pp.10-11.

14. Sladkopevtsev SA (1973) Razvitie rechnykh dolin i neotektonika. - Moscow: Nedra, 1973. $-132 \mathrm{p}$.

15. Suvorov AI (1963) Razlomy i gorizontal'nye dvizheniya zemnoy kory. - Moscow: Izd. AN SSSR, 1963, pp.173-237.

16. Favorskaya MA (1971) Global'nye zakonomernosti razmeshcheniya krupnykh rudnykh mestorozhdeniy. Sov. Geologiya 1971 - № 11 - pp. 19-26.

17. Filosofov VP (1975) Osnovy morfometricheskogo metoda poiskov tektonicheskikh struktur. - Saratov: Izd-vo Saratov. un-ta, 1975. - $232 \mathrm{p}$.

18. Khain VE (1967) K teoreticheskim osnovam strukturno-geomorfologicheskogo metoda. Strukturno-geomor. Issledovaniya. L.: Nedra, 1967, pp.15-23.

19. Khetagurova VS (2014) Erozionno-strukturnyy analiz - kak vspomogatel'nyy metod pri poiskakh mestorozhdeniy poleznykh iskopaemykh. Teoreticheskie i prakticheskie issledovaniya XXI veka. Trudy mezhdunarodnoy nauchno-prakticheskoy konferentsii. Moscow: IIU MGOU, 2014. pp. 629-634.

20. Khetagurova VS (2014) Klassifikatsiya erozionnykh sistem, modeli, struktury. Dostizheniya vuzovskoy nauki. Trudy mezhdunarodnoy nauchno-prakticheskoy konferentsii. - Moscow: IIU MGOU, 2014. pp.201-204

21. Khripkov AV, Volkov EL (1973) Nekotorye osobennosti dolin kak geomorfologicheskie poiskovye priznaki rudnykh mestorozhdeniy. Izd. Dnepropetrovskogo otd. Geogr. Ob-va Ukrainy, 1973, vyp. 3, pp.18-25.

22. Chernova YI, Nugmanov II, Dautov AN (2010) Primenenie analiticheskikh funktsiy GIS dlya usovershenstvovaniya i razvitiya strukturnomorfologicheskikh metodov izucheniya neotektoniki. Geoinformatika. — 2010. — № 4. - pp. 9-22.

23. Shchul'ts SS (1964) Geostrukturnye oblasti i polozhenie $\mathrm{v}$ strukture Zemli oblastey goroobrazovaniya po dannym noveyshey tektoniki SSSR. - V kn.: Aktivizirovannye zony zemnoy kory, noveyshie tektonicheskie dvizheniya i seysmichnost'. - Moscow: Nauka, 1964, pp.47. 
Impact Factor ISRA (India) $\quad=1.344$

Impact Factor ISI (Dubai, UAE) $=\mathbf{0 . 8 2 9}$

based on International Citation Report (ICR)

Impact Factor GIF (Australia) $\quad \mathbf{0} \mathbf{0 . 3 5 6}$

24. Khetagurova VS, Umaraliev RA, Bryukhanova GA (2015) The use of erosion-structural analysis on the example of mountainous territory. "The First European Conference on Earth Sciences". Proceedings of the Congress (February 25, 2015) "East West" Association $\begin{array}{lr}\text { Impact Factor JIF } & =\mathbf{1 . 5 0 0} \\ \text { Impact Factor SIS (USA) } & =\mathbf{0 . 9 1 2} \\ \text { Impact Factor PИНЦ (Russia) } & =\mathbf{0 . 1 7 9} \\ \text { Impact Factor ESJI (KZ) } & =\mathbf{1 . 0 4 2}\end{array}$

for Advanced Studies and Higher Education GmbH. Vienna. 2015. pp. 35-39.

25. Schumm SA (1977) The Fluvial System. New York: John Wiley and Sons, 1977. — 338 p. 